\title{
Pes Cavus and Idiopathic Scoliosis from School Screening
}

\section{Hanène Belabbassi ${ }^{1 *}$, Assia Haddouche ${ }^{2}$, Abdelkader Ouadah ${ }^{3}$ and Houria Kaced ${ }^{1}$}

${ }^{1}$ Department of Physical Medicine and Rehabilitation, Hospital Specialized Establishment Bounaama Djilali, Rue des halim brothers Douéra, Algiers. Saad Dahleb University, Faculty of Medicine, BP 270 Route de Soumaa, Blida, Algeria

${ }^{2}$ Department of Rheumatology, Etablissement Public Hospitalier de Blida, Kritli Avenue Mokhtar, Blida. Saad Dahleb University, Faculty of Medicine, BP 270 Route de Soumaa, Blida, Algeria

${ }^{3}$ National Centre of Equipment to Disabled War of National Liberation, Douéra, Algiers, Algeria

\section{Abstract}

Background context: The correlation of idiopathic scoliosis and cavus foot has been previously reported. This has been ascribed to possible lesions related to muscular imbalance influenced by the central nervous system.

Purpose: Our study goal is to assess and compare the rate of pes cavus in children with and without scoliosis.

Study design: Prospective, cross-sectional; Case-control study.

Patient sample: 81 subjects, 42 healthy children matched for age and gender with 39 children with idiopathic scoliosis.

Outcome measures: Clinical examination of the trunk and the feet, radiological assessment of the spine. The statistical analysis was performed using SPSS package.

Methods: Children were examined from a school-screening program at the physical medicine and rehabilitation department in the university hospital of Douéra, in Algiers. A number of measurements were assessed including the trunk asymmetry in standing forward bend followed by the Cobb angle in upright spine radiography and the footprints analysis under weight-bearing on the podoscope (mirror table).

Results: There is a statistically significant difference of pes cavus rate in children without idiopathic scoliosis and those with idiopathic scoliosis. Comparing $55.8 \%$ to $33.3 \%$ we found Chi-square $=4.174$ with $P=0.043$.

Conclusions: In our small sample, the significant difference between pes cavus in children without and with idiopathic scoliosis was noted, as it has been elsewhere reported. The percentage of cavus foot was traced higher in the healthy children than it is in the moderate scoliosis curves studied.

Keywords: Adolescent idiopathic scoliosis; Pes cavus; School screening

\section{Introduction}

Pes cavus is a high arch in the sagittal plane of the foot that does not flatten with weight bearing [1]. It may be idiopathic in $20 \%$ of cases [2] and caused by malunion of calcaneal or talar fractures, burns, sequelae resulting from compartment syndrome, residual clubfoot and neuromuscular disease in $80 \%$ of cases [3]. Pes cavus or high-arched foot is rarely seen at birth or in the first year of life. There is a rare, benign form of high-arched foot called pes arcuatus, which is seen in the first year of life and tends to be an isolated entity, which resolves with time. The majority of feet develop cavus deformity in the first or second decade of life [4]. Adolescents Idiopathic Scoliosis (AIS) is the most common deformity seen in spine clinics for adolescents [5].

The AIS is an entity of scoliosis with no defines etiology. It is a progressive three dimensional spine deformity with vertebral rotation causing clinically the rib hump and a modification of a physiologic sagittal plane of the trunk. AIS involve a deformation and disorientation of the thoracic cage that accompanies the lateral deviation and rotation of the spinal column [6]. This pathology presents a high risk of aggravation during a growth period [7].

A new risk classification rule for curve progression in AIS identified four risk groups of curve progression. Patients with a curvature of $26^{\circ}$ and more and less than $18^{\circ}$ constituted the highest and lowest risk groups, respectively. The two intermediate groups were identified by the age (11.3 years), menarcheal status, and body height $(154 \mathrm{~cm})$ [8].

A school screening program helps to diagnose little spine curves in a young age. This early diagnostic prevent the quick aggravation of this spine deformity during growth. The effectiveness of screening is based upon the reduction in the number of cases requiring surgery, following aggressive screening and bracing [9].

Studying AIS together with pes cavus is used in a number of neuromuscular diseases (e.g., muscular dystrophy, cerebral palsy, friedrich's ataxia, charcot-marie-tooth disease, poliomyelitis, syringomyelia, spinal cord tumors etc) as these pathologies are thought to share common origins, share common etiology linked to muscle imbalance, and as often pointed out in numerous investigations [10], patients with scoliosis are more likely to have cavus foot [11]. So, what is the degree of association between idiopathic adolescent scoliosis and cavus foot?

This study aims to assess the rate of pes cavus in children with and without scoliosis and show if there is a significant difference between the two rates. It is beyond the scope of this study to elucidate the pathology and etiology of scoliosis cases.

*Corresponding author: Hanène Belabbassi, Department of Physical Medicine and Rehabilitation, Hospital Specialized Establishment Bounaama Djilali, Rue des halim brothers Douéra, Algiers. Saad Dahleb University, Faculty of Medicine BP 270 Route de Soumaa, Blida, Algeria, Tel: +213-661-531-314; E-mail: goodhealth60@hotmail.com

Received December 10, 2013; Accepted January 08, 2014; Published January 11,2014

Citation: Belabbassi H, Haddouche A, Ouadah A Kaced H (2014) Pes Cavus and Idiopathic Scoliosis from School Screening. J Spine 3: 152. doi:10.4172/21657939.1000152

Copyright: (C) 2014 Belabbassi $\mathrm{H}$, et al. This is an open-access article distributed under the terms of the Creative Commons Attribution License, which permits unrestricted use, distribution, and reproduction in any medium, provided the original author and source are credited. 
Citation: Belabbassi H, Haddouche A, Ouadah A Kaced H (2014) Pes Cavus and Idiopathic Scoliosis from School Screening. J Spine 3: 152. doi:10.4172/2165-7939.1000152

Page 2 of 5

\section{Patients and Methods}

\section{Design and subjects}

We performed a prospective, cross-sectional; case-control study within a school screening program managed during a 2-year period between 2011 and 2012 at the department of physical medicine and rehabilitation, in Algiers, Algeria. A total of 81 children were examined in our sample: 39 with adolescent idiopathic scoliosis and 42 control subjects. All patients were recruited from school screening program. Consent was obtained from all and the ethics committee approved the study.

The inclusion criteria for patient were age and the Cobb angle. School children between the ages of 6 and 17 years old were selected. When a Cobb angle of the curves on spine radiography was greater than $10^{\circ}$ the patient screened were considered having scoliosis and were included in the study. Exclusion criteria were patients with evidence of abnormalities, thoracic deformity related to others pathologies such as Marfan disease, congenital spine abnormalities, skeletal dysplasia, neuromuscular diseases and other types of scoliosis.

When children within the same group age are found healthy with no known diseases and no 2 history of any disease, they served as control subjects. Both healthy and scoliotic subjects were examined for cavus foot and were separated in the analysis as comparing groups with and without cavus foot.

\section{Assessment}

Clinical examination: Scoliosis and cavus foot are screened systematically in school children. We took randomly a sample of 81 patients mixed between children with and without scoliosis. The clinical examination was done in ambient temperature, on undressed child, standing upright, with complete extension of the knee, hind foot joint together and forefoot making $30^{\circ}$.

The Adams forward bend test is very important in the screening of Adolescent Idiopathic Scoliosis "AIS". The patient bends forward at the waist, with the arms relaxed, hand in front of the other, while the physician inspects from a posterior to anterior view for the trunk asymmetry (the location of the rib hump) using a scoliometer. Before this test is performed it needs to eliminate any pelvic tilt due to leg length inequality. A difference in relative position of the iliac crest may be a sign of an anatomic leg-length discrepancy, or a functional leglength discrepancy from a condition such as sacroiliac joint dysfunction or scoliosis [12].

Up to $25 \%$ of normal adolescents have clinical evidence of a spinal deformity in the forward bending position. However, more than $40 \%$ of the deformities so detected are secondary to the presence of a pelvic tilt. These small, non-progressive, predominantly lumbar curves occur with equal frequency in both sexes and in both directions. A pilot study showed that pelvic asymmetry, leg length inequality, or both in combination were the cause of the pelvic tilt [13].

We must not include the scoliotic attitude which is a lateral deviation of the spine without rotation. The scoliotic attitude is not equal to AIS; one is a deviation of the spine in one plan, the frontal one, and the second is a tridimensional deformity. In our study, we underline this distinction to say that we have included only the AIS in a scoliotic group. It means that all curves diagnosed on X-ray examination without vertebral rotation are considered a non scoliotic subject. We checked the disappearance of the trunk asymmetry reflecting clinically a vertebral rotation on subject in the prone position with the legs placed
8 out of the examination table. This trunk asymmetry disappearance is in favor of scoliotic attitude.

The diagnosis of pes cavus was done in all school children under weight-bearing through a podoscope (mirror table) using a footprint mat to type a cavus foot grade [14-16]. Foot prints classification of the pes cavus on podoscope is illustrated in Figure 1. Two groups of patients those with pes cavus and the other control group without pes cavus was compared.
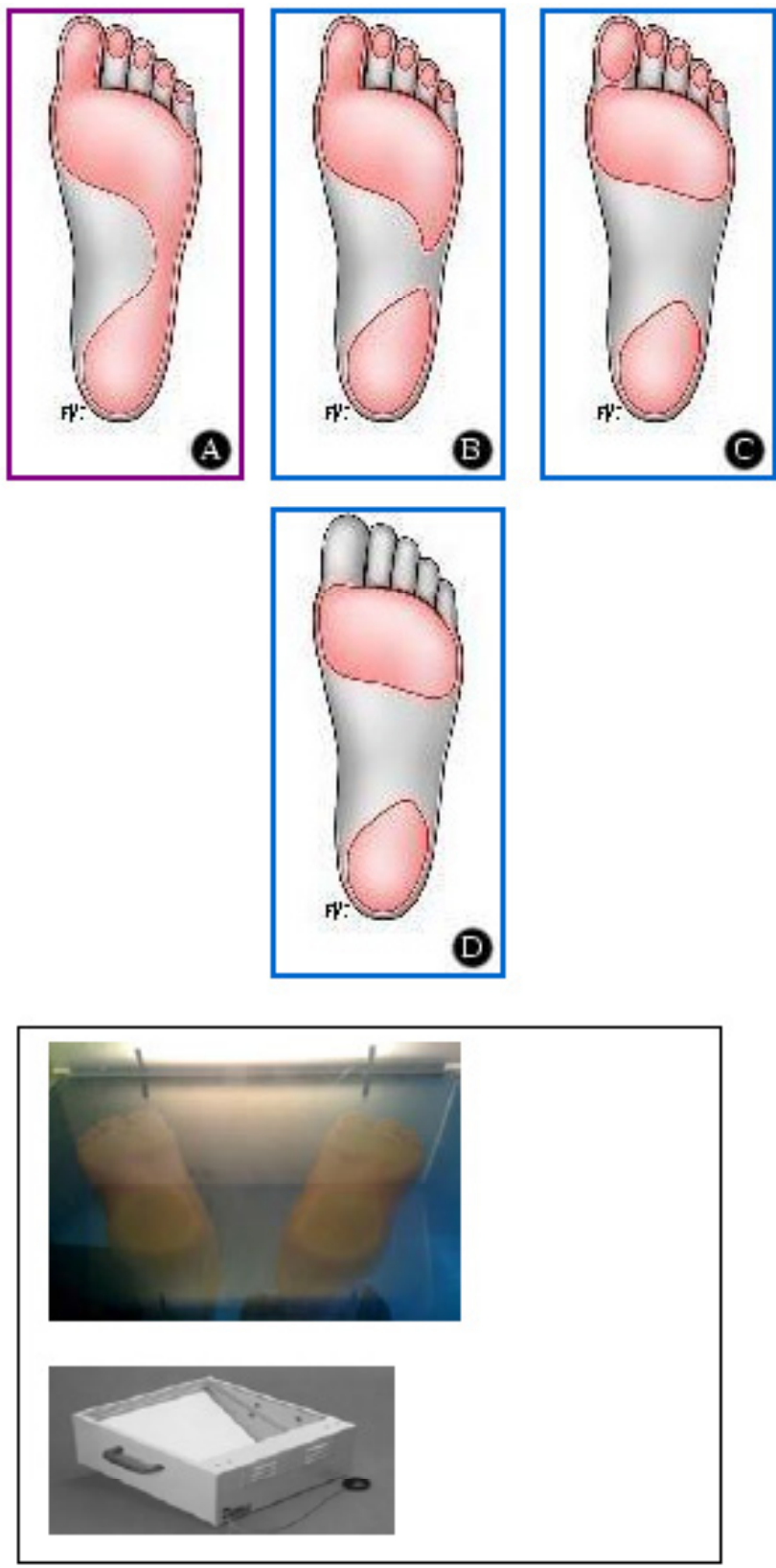

Figure 1: Pes cavus foot print: (A) pes cavus at the first level with a decrease of the isthmus between the front and rear supports, become less than one third of the width of the foot, (B) pes cavus in the second degree, the Isthmus of lateral support is interrupted with partial persistence extensions of anterior and posterior support, and $(C)$ pes cavus in the third degree with complete loss of lateral support strip and (D) pes cavus in the third degree with a loss of pulp support related to toe claws [16]. 
Citation: Belabbassi H, Haddouche A, Ouadah A Kaced H (2014) Pes Cavus and Idiopathic Scoliosis from School Screening. J Spine 3: 152. doi:10.4172/2165-7939.1000152

Page 3 of 5

X-ray assessment: For all children with trunk asymmetry we performed a standard standing radiograph of the spine to confirm the diagnosis of scoliosis by measuring a Cobb angle. Scoliosis is defined by Cobb angle equal to $10^{\circ}$ or more [17]. Following the Lenke classification $[18,19]$ (Figure 2) the scoliosis localization was determined.

Two groups of patients those with idiopathic scoliosis and the other control group without idiopathic scoliosis was compared.

\section{Statistical analysis}

We used the Statistical Package for the Social Sciences software (SPSS Version 20.0) to calculate the Chi-square test to compare tow percentages and the Student's t test to compare two means. The cut off mark of our level of significance is set to alpha equal to $13.5 \%$.

\section{Results}

\section{Population characteristics}

81 school children between the age of 6 and 17 years old were screened for the presence of a spinal deformity and 162 feet of those 81 children were examined for pes cavus. About $59.3 \%$ of the children screened were girls. The mean age of the population is $12.21 \pm 2.25$ years old. The body mass index is about $16.87 \pm 2.55 \mathrm{~kg} / \mathrm{m}^{2}$ and the pubertal age of the population is $12.62 \pm 1.33$ years.
When comparing the scoliotic school children with the healthy control (Table 1) we did not find a significant difference in the gender distribution or the pubertal ages, but we found that the scoliotic children were older than the healthy control group with $\mathrm{p}<0.001$. We have also noted that the scoliotic school children are heavier than the healthy control group. This might be related to the difference in age. There is a chance we have not diagnosed AIS in the healthy control group due to their young age.

\section{Baseline characteristics}

Our sample includes 81 children. 36 of these children have Pes cavus and of these 36, 29 have cavus foot on both sides and 7 have cavus foot on either the left or the right side. So, $80 \%$ of the diagnosed pes cavus are bilateral (Figure 3).

The percentage of spinal deformity in our sample is $48.1 \%$ (39 children out of 81 are scoliotic).

\section{Footprint types}

The predominant footprint types in children with pes cavus were of Grade 1 (light cavus foot) (Table 2).

\section{Scoliosis curve location}

The mean Cobb angle in children with AIS is about $18.15^{\circ} \pm 10.10^{\circ}$

\begin{tabular}{|c|c|c|c|c|}
\hline \multicolumn{5}{|c|}{ Curve Type } \\
\hline Type & $\begin{array}{l}\text { Proximal } \\
\text { Thoracic }\end{array}$ & $\begin{array}{c}\text { Main } \\
\text { Thoracic }\end{array}$ & $\begin{array}{c}\text { Thoracolumbar I } \\
\text { Lumbar }\end{array}$ & $\begin{array}{l}\text { Curve } \\
\text { Type }\end{array}$ \\
\hline 1 & Non-Structural & Structural (Major") & Non-Structurai & Main Thoracic (MT) \\
\hline 2 & Structural & Structural (Majorn & Non-Structural & Double Thoracic (DT) \\
\hline 3 & Non-Structural & Structural (Major) & Structural & Doubie Major (DM) \\
\hline 4 & Structural & Structural (Major") & Structural & Triple Major (TM) \\
\hline 5 & Non-Structural & Non-Structural & Structural (Major) & Thoracolumbar / Lumbar (TUL) \\
\hline 6 & Non-Structural & Structural & Structural (Major") & $\begin{array}{l}\text { Theracolumbar / Lumbar - } \\
\text { Main Thoracic (TLL - MT) }\end{array}$ \\
\hline
\end{tabular}

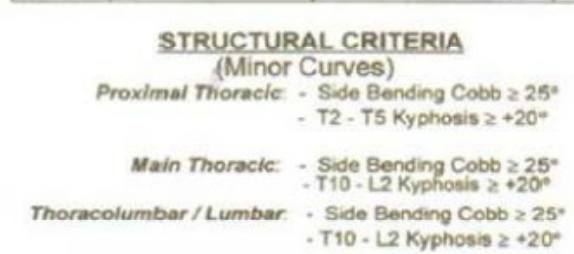

"Major = Largest Cobb Measurement, always structural

Minor = all other curves with structural criteria applied
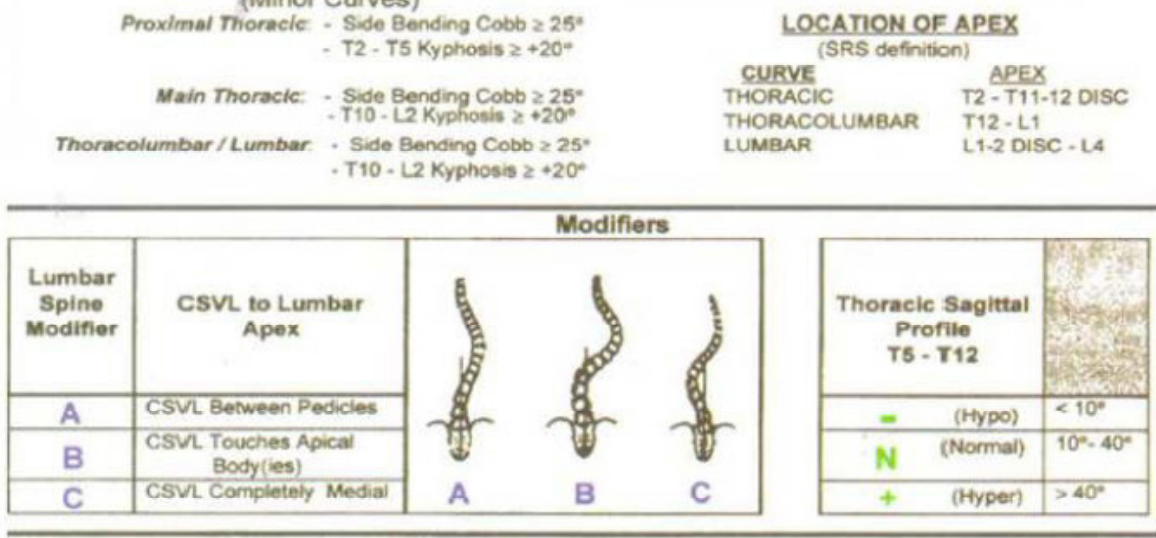

Curve Type (1-6) + Lumbar Spine Modifier (A, B, or C) + Thoracic Sagittal Modifier ( , N, or *)

Classification (0.g.1B+):

Figure 2: Classification of adolescent idiopathic scoliosis.

\begin{tabular}{|c|c|c|c|}
\hline Variables & AIS (N = 39) & Control (N=42) & p-value \\
\hline Girls / Boys & $27 / 12$ & $11.38 \pm 2.16$ \\
\hline Age (years) & $13.10 \pm 2.01$ & $12.83 \pm 1.27$ \\
\hline Puberty Age & $12.5 \pm 1.38$ & $16.15 \pm 2,42$ \\
\hline BMI $\left(\mathbf{K g} / \mathbf{m}^{2}\right)$ & $17.64 \pm 2.48$ & NS \\
\hline
\end{tabular}

Table 1: Population Characteristics. 
Citation: Belabbassi H, Haddouche A, Ouadah A Kaced H (2014) Pes Cavus and Idiopathic Scoliosis from School Screening. J Spine 3: 152. doi:10.4172/2165-7939.1000152

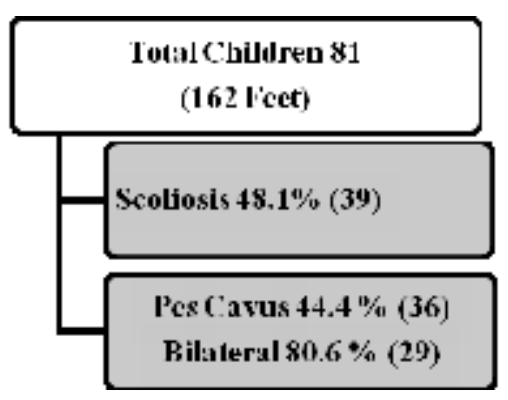

Figure 3: Representative shaft of school children rate with scoliosis and school children rate with cavus foot in the total sample [18].

\begin{tabular}{|c|c|}
\hline & Pes Cavus $(\mathrm{N}=\mathbf{6 5}) \mathrm{n}(\%)$ \\
\hline Grade 1 & $54(\mathbf{8 3 . 0 7})$ \\
\hline Grade 2 & $11(\mathbf{1 6 . 9 2})$ \\
\hline
\end{tabular}

Table 2: Footprint Types.

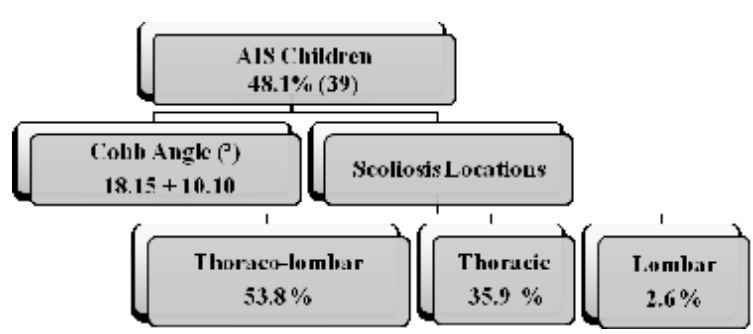

Figure 4: Regression tree of different scoliosis curve location rates and a mean Cobb angle in scoliotic children. Not shown is the double curve scoliosis location.

and the spinal deformity location the most often noted is the thoracolombar (Figure 4).

\section{The statistical comparison of pes cavus and AIS}

There is a statistically significant difference (Chi-square $=4.174$ with $\mathrm{P}=0.043$ ) of pes cavus rate in children without idiopathic scoliosis $55.8 \%$ and those with idiopathic scoliosis $33.3 \%$ (Table 3 ).

\section{The statistical comparison of pes cavus grade and AIS}

Foot examination diagnosed cavus foot in 25 out of the 78 feet of scoliotics patients including 5 typical and 20 light cavus foot. While 39 out of 84 feet were diagnosed in non 9 scoliotic patients, with 6 typical and 33 light cavus foot.

There is non-significant difference between the two groups (Table 4 ), which means for our sample, the pes cavus are more present in the healthy control than the scoliotic patients.

\section{The statistical comparison of pes cavus in scoliotic children}

The Cobb angle was significantly more important in the group of scoliotic children without pes cavus than in the group of scoliotic children with pes cavus (Table 5). The location of the scoliosis curve between the two groups did not show any statistical significant difference (Table 6).

\section{Discussion}

My review of other work on scoliosis and pes cavus relationship revealed that our study compared to that of Grivas et al., [10] on a much larger sample $(\mathrm{N}=3544)$, where he found that pes cavus are more present in the healthy control than the scoliotic patients. Others, such as Carpentiro et al., [11] have shown that pes cavus are frequent in scolitic patients (Table 7). However, Barros et al., in a Brazilian study did not observe any statistical significance difference between the two groups. The first one included 48 patients with idiopathic scoliosis, and the second group (control) included 48 patients with similar ages as those in the first group. Radiographs were taken to determine the type of scoliosis curve and its location and magnitude. The incidence and degree of pes cavus were established by means of footprints. Statistical analyses were performed and did not display significant correlation between scoliosis and pes cavus, nor between the magnitude of the curve and pes cavus [20].

\section{Summary and Conclusion}

In our small sample, the spinal deformity constituted $48.1 \%$ of the population. The mean cobb angle in children with AIS is about $18.15^{\circ}$ $\pm 10.10^{\circ}$ and the spinal deformity location the most often noted is the thoraco-lumbar. The scoliotic school children were significantly older and heavier than the healthy control group. When we randomly selected the patients, we might not have diagnosed AIS in the control group due to their young age.

We found pes cavus in 36 children out of 81 with $80 \%$ bilateral. The predominant footprint 10 types in children with pes cavus were of grade 1 (light cavus foot).

In our small sample, the significant difference between pes cavus in children without and with idiopathic scoliosis was noted, as it has been elsewhere reported. The percentage of cavus foot was traced higher in the healthy children than it is in the moderate scoliosis curves studied. Comparing $55.8 \%$ to $33.3 \%$ we found chi-square $=4.1748$ with $p=0.043$, which suggests that more parameters need to be investigated in future studies. For example, what about the local imbalance in the muscular function?

\begin{tabular}{|c|c|c|c|}
\hline & $\begin{array}{c}\text { Scoliosis group } \\
(N=39) n(\%)\end{array}$ & $\begin{array}{l}\text { Healty control } \\
(\mathrm{N}=42) \quad n(\%)\end{array}$ & $p$-value \\
\hline Pes cavus $(\mathrm{N}=36)$ & $13(33.3)$ & $23(55.8)$ & 0.043 \\
\hline
\end{tabular}

Table 3: Statistical Comparison of Pes Cavus and AIS.

\begin{tabular}{|l|c|c|c|}
\hline & AIS (N=78) $\mathbf{n}(\mathbf{\%})$ & Control (N=84) $\mathbf{n}(\%)$ & $\boldsymbol{p}$-value \\
\hline Pes Cavus & $25(32)$ & $39(46.4)$ & 0.043 \\
\hline Grade I & $20(80)$ & $33(84.6)$ & NS \\
\hline Grade II & $5(20)$ & $6(15.4)$ & NS \\
\hline
\end{tabular}

Table 4: Statistical Comparison of Pes Cavus Grade and AIS.

\begin{tabular}{|l|c|c|c|}
\hline & Pes Cavus $(\mathrm{N}=13)$ & Control $(\mathrm{N}=26)$ & $p$-value \\
\hline Cobb angle $\left({ }^{\circ}\right)$ & $13.69 \pm 5.82$ & $20.38 \pm 11.10$ & 0.018 \\
\hline
\end{tabular}

Table 5: Statistical Comparison of Pes Cavus and Cobb Angle in Scoliotic Children.

\begin{tabular}{|l|c|c|c|}
\hline Scoliosis Location & Pes Cavus $(\mathrm{N}=13)$ & Control $(\mathrm{N}=26)$ & $p$-value \\
\hline Thoraco Lombar & 8 & 13 & NS \\
\hline Thoracic & 4 & 11 & NS \\
\hline Lombar & 1 & 2 & NS \\
\hline
\end{tabular}

Table 6: Statistical Comparison of Pes Cavus and Curve Localization in Scoliotic Children.

\begin{tabular}{|c|c|c|c|}
\hline & $\begin{array}{c}\text { This Study } \\
\mathrm{N}=82 \\
\text { (6-17 years old) }\end{array}$ & $\begin{array}{l}\text { Carpintero } P^{*} \\
\quad \mathrm{~N}=540 \\
\text { (Adolescents) }\end{array}$ & $\begin{array}{c}\text { Grivas } \text { TB }^{* *} \\
N=3544 \\
(6-18 \text { years old })\end{array}$ \\
\hline Pes Cavus & $\begin{array}{l}\text { Control } \\
P=0.043\end{array}$ & $\begin{array}{c}\text { AIS } \\
P<0.01\end{array}$ & $\begin{array}{l}\text { Control } \\
P<0.05\end{array}$ \\
\hline
\end{tabular}

Table 7: Study Comparison. 
Citation: Belabbassi H, Haddouche A, Ouadah A Kaced H (2014) Pes Cavus and Idiopathic Scoliosis from School Screening. J Spine 3: 152. doi:10.4172/2165-7939.1000152

Page 5 of 5

\section{References}

1. Wapner KL, Myerson MS (2000) Pes cavus. In: Myerson MS, ed. Foot and Ankle Disorders. Philadelphia, Pa: WB Saunders.

2. Maynou C, Naudi S (2010) Pied creux idiopathique. Les grandes déformations du pied de l'enfant et de l'adulte 175-180.

3. Wicart P (2012) Pied creux, du nouveau-né à l'adolescent. Review Article. Revue de Chirurgie Orthopédique et Traumatologique 98: 728-743.

4. Fixsen JA (1996) Pes cavus. The Foot 6: 112-115.

5. Mahaudens P, Thonnard JL, Detrembleur C (2005) Influence of structural pelvic disorders during standing and walking in adolescents with idiopathic scoliosis. Spine J 5: 427-433.

6. Zabjek KF, Leroux MA, Coillard C, Rivard CH, Prince F (2005) Evaluation of segmental postural characteristics during quiet standing in control and Idiopathic Scoliosis patients. Clinical Biomechanics 20: 483-490.

7. Khouri N, Vialle R, Mary P, Marty C (2004) Scoliose idiopathique. Stratégie diagnostique, physiopathologie et analyse de la déformation. Encyclopédie médico-chirurgicale Appareil locomoteur Rhumatologie-Orthopédie 1: 17-44.

8. Lee CF, Fong DY, Cheung KM, Cheng JC, Ng BK, et al. (2012) A new risk classification rule for curve progression in adolescent idiopathic scoliosis. Spine J 12: 989-995

9. Roubal PJ, Freeman C, Placzek J (1998) Costs and Effectiveness of Scoliosis Screening. Physiotherapy 85: 259-268.

10. Grivas TB, Stavlas P, Koukos K, Samelis P, Polyzois B (2002) Scoliosis and cavus foot. Is there a relationship? Study in referrals, with and without scoliosis, from school screening. Stud Health Technol Inform 88: 10-14.
11. Carpintero P, Entrenas R, Gonzalez I, Garcia E, Mesa M (1994) The relationship between pes cavus and idiopathic scoliosis. Spine (Phila Pa 1976) 19: 12601263.

12. Young CC, Niedfeldt MW, Morris GA, Eerkes KJ (2005) Clinical examination of the foot and ankle. Prim Care 32: 105-132.

13. Walker AP, Dickson RA (1984) School screening and pelvic tilt scoliosis. Lancet 2: 152-153.

14. Bouysset M (1987) L'examen de l'empreinte plantaire est-il désuet? MédChir Pied 3: 89-91.

15. Goldcher A (2012) Examen Clinique. Podologie ( $\left.6^{\text {th }} e d n\right)$.

16. Cruvale C, Rochwerger A (2002) Pieds creux EncyclMédChir (Editions Scientifiques et Médicales Elseviers SAS, Paris, tous droits réservés), Appareil locomoteur, 14-112-A-10, Podologie.

17. Raudenbush B, Simela A, Hans J (2013) A review of the evaluation, diagnosis, and nonsurgical treatment of adolescent idiopathic scoliosis. Review Article Osteopathic Family Physician 5: 158-168

18. Lenke LG (2007) The Lenke classification system of operative adolescent idiopathic scoliosis. Neurosurg Clin N Am 18: 199-206.

19. Lenke LG, Betz RR, Clements D, Merola A, Haher T, et al. (2002) Curve prevalence of a new classification of operative adolescent idiopathic scoliosis: does classification correlate with treatment? Spine (Phila Pa 1976) 27: 604611

20. Barros PE, Oliveira CEAS, Souza Nery CA (1997) Study of the association pes cavus-idiopathic scoliosis. Revista Brasileira de Ortopedia 32: 93-99. 